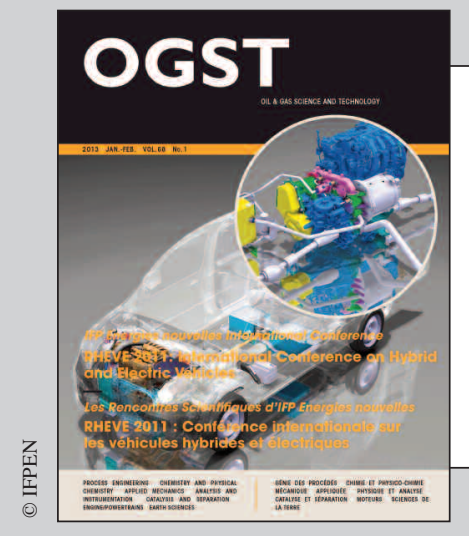

Dossier

This paper is a part of the hereunder thematic dossier published in OGST Journal, Vol. 68, No. 1, pp. 3-178 and available online here

Cet article fait partie du dossier thématique ci-dessous publié dans la revue OGST, Vol. 68, n 1 , pp. 3-178 et téléchargeable ici

DOSSIER Edited by/Sous la direction de : A. Sciarretta, F. Badin et J. Bernard RHEVE 2011 : International Conference on Hybrid and Electric Vehicles RHEVE 2011 : Conférence internationale sur les véhicules hybrides et électriques

Oil \& Gas Science and Technology - Rev. IFP Energies nouvelles, Vol. 68 (2013), No. 1, pp. 3-178

Copyright (C) 2013, IFP Energies nouvelles

\section{$3>$ Editorial}

$13>$ Analysis and Experimental Implementation of a Heuristic Strategy for Onboard Energy Management of a Hybrid Solar Vehicle

Analyse et expérimentation d'une stratégie heuristique pour la gestion d'énergie à bord d'un véhicule hybride solaire

G. Coraggio, C. Pisanti, G. Rizzo and M. Sorrentino

23 > Open Issues in Supervisory Control of Hybrid Electric Vehicles: A Unified Approach Using Optimal Control Methods

Questions ouvertes sur la supervision énergétique des véhicules hybrides électriques : une approche unifiée par la théorie de la commande optimale

L. Serrao, A. Sciarretta, 0. Grondin, A. Chasse, Y. Creff, D. Di Domenico, P. Pognant-Gros, C. Querel and L. Thibault

35 > Optimization of Hybrid Power Trains by Mechanistic System Simulations

Optimisation de groupes motopropulseurs électriques hybrides par simulation du système mécanique

T. Katrašnik and J.C. Wurzenberger

51 > A Phenomenological Heat Transfer Model of SI Engines - Application to the Simulation of a Full-Hybrid Vehicle

Un modèle phénoménologique de transfert thermique au sein de moteurs à allumage commandé - Application à la simulation d'un véhicule full-hybride

R. Dubouil, J.-F. Hetet and A. Maiboom

$65>$ Battery Electric Vehicle (BEV) or Range Extended Electric Vehicle (REEV)? - Deciding Between Different Alternative Drives Based on Measured Individual Operational Profiles

Véhicule électrique à batteries (BEV) ou véhicule électrique à prolongateur d'autonomie (REEV) ? - Choisir entre différents entrânements alternatifs sur la base de profils opérationnels individuels mesurés

S. Marker, B. Rippel, P. Waldowski, A. Schulz and V. Schindler

$79>$ Assessment by Simulation of Benefi ts of New HEV Powertrain Configurations

Évaluation par simulation des bénéfi ces de nouvelles chaînes de traction hybrides

N. Kim and A. Rousseau
95 > Dual Mode Vehicle with In-Wheel Motor: Regenerative Braking Optimization

Véhicule bi-mode avec moteurs roues : optimisation du freinage récupératif

G. Le Solliec, A. Chasse, J. Van-Frank and D. Walser

109 > Engine Downsizing and Electric Hybridization Under Consideration of Cost and Drivability

Réduction de taille moteur et hybridation électrique avec considérations de coût et de performance de conduite

S. Ebbesen, P. Elbert and L. Guzzella

117 > Representative Midwestern US Cycles: Synthesis and Applications Cycles représentatifs du Middle West américain : synthèse et applications

T.-K. Lee and Z.S. Filipi

127 > A Review of Approaches for the Design of Li-lon BMS Estimation Functions

Revue de différentes approches pour l'estimation de l'état de charge de batteries Li-ion

D. Di Domenico, Y. Creff, E. Prada, P. Duchêne, J. Bernard and V. Sauvant-Moynot

137 > Experimental Assessment of Battery Cycle Life Within the SIMSTOCK Research Program

Évaluation expérimentale de la durée de vie de la batterie dans le programme de recherche SIMSTOCK

P. Gyan, P. Aubret, J. Hafsaoui, F. Sellier, S. Bourlot, S. Zinola and F. Badin

$149>$ Smart Battery Thermal Management for PHEV Efficiency Une gestion avancée de la thermique de la batterie basse tension de traction pour optimiser l'efficacité d'un véhicule hybride électrique rechargeable

L. Lefebvre

$165>$ Parameterization and Observability Analysis of Scalable Battery Clusters for Onboard Thermal Management

Paramétrage et analyse d'observabilité de clusters de batteries de taille variable pour une gestion thermique embarquée

Xinfan Lin, Huan Fu, Hector E. Perez, Jason B. Siege, Anna G. Stefanopoulou, Yi Ding and Matthew P. Castanier 


\title{
Engine Downsizing and Electric Hybridization Under Consideration of Cost and Drivability
}

\author{
S. Ebbesen*, P. Elbert and L. Guzzella \\ Institute for Dynamic Systems and Control, ETH Zurich, 8092 Zurich - Switzerland \\ e-mail: sebbesen@idsc.mavt.ethz.ch -elbertp@ethz.ch - guzzella@ethz.ch \\ * Corresponding author,
}

\begin{abstract}
Résumé - Réduction de taille moteur et hybridation électrique avec considérations de coût et de performance de conduite - Les constructeurs de véhicules automobiles électriques hybrides sont confrontés au problème délicat de l'optimisation multiobjectifs de la réduction de taille moteur et de l'hybridation électrique, tout en considérant le coût et la performance de conduite. Les solutions à ce problème de dimensionnement moteur sont généralement obtenues par des méthodes de conception de type heuristique. Cependant, afin d'obtenir des solutions optimales globales, il est nécessaire de recourir aux formalismes théoriques d'optimisation. Dans cet article, nous présentons une méthodologie de travail, qui s'appuie sur les théories classiques d'optimisation, pour le dimensionnement optimal des composants d'une chaîne de traction électrique hybride. En outre, cette approche est flexible afin de permettre l'ajout d'un nombre quelconque d'objectifs, comme la minimisation de la consommation d'essence, le coût de l'hybridation, les niveaux d'émission et (ou) la maximisation des performances d'accélération. Sur la base de ce cadre de travail, nous présentons un certain nombre de techniques et d'outils pour l'analyse, l'acceptation, l'amélioration ou le rejet des solutions proposées au problème du dimensionnement optimal.
\end{abstract}

\begin{abstract}
Engine Downsizing and Electric Hybridization Under Consideration of Cost and Drivability - Automotive manufacturers of hybrid electric vehicles are confronted with the multiobjective non-trivial optimization problem of engine downsizing and electric hybridization under consideration of cost and drivability. Solutions to this sizing problem are typically reached by heuristic design methodologies. However, a design approach formalized in an optimization theoretical setting is necessary in order to obtain globally optimal solutions. In this paper, we present a framework for optimal sizing of hybrid electric drivetrain components. This framework is cast within standard optimization theory. Moreover, it is flexible in order to easily include any number of objectives, such as minimization of fuel consumption, cost of hybridization, emission levels and (or) maximization of acceleration performance. Based on this framework, we demonstrate a number of techniques and tools to analyze, accept, improve, or reject the proposed solutions to the optimal sizing problem.
\end{abstract}




\section{INTRODUCTION}

Engine downsizing and electric hybridization are concepts commonly used to improve fuel economy of vehicles. However, specifications on performance and acceptable cost impose constraints on the extent to which these concepts can be exploited. For example, engine downsizing improves engine efficiency due to an increase in the relative load. However, measures that are important for consumer acceptance, such as top speed and acceleration performance, are degraded by the inherent reduction in power available for traction. An electric storage system and one or more electric machines may be added to make up for the loss of tractive power. Electric hybridization also enables other fuel saving modes such as braking energy recuperation, operating point shifting, zero-emission driving, etc. Yet, the electric components, in particular batteries, remain expensive and may, from a cost perspective, quickly render the vehicle unattractive to potential costumers. Thus, automotive manufacturers are confronted with the multi-objective optimization problem of sizing the drivetrain components such that fuel consumption is minimized while specifications on performance and cost are met.

In this paper, we investigated possible solutions to this optimization problem. The parameters subject to optimization were the engine displacement volume, electric motor power, and battery capacity. The objective function to be minimized was defined as the weighted sum of three terms: fuel consumption over a given driving cycle; the total monetary cost of the engine, motor and battery; and vehicle acceleration performance. The fuel consumption associated with a given triple of parameters was computed using dynamic programming. This technique guarantees to yield the global minimum. Consequently, the solution to the sizing problem is not influenced by the energy management strategy.

The paper is organised in the following way: in Section 1, the problem is formulated; in Section 2, we explain the methodology used to solve the problem; in Section 3, the results are presented and discussed, and finally, we state our conclusions.

\section{PROBLEM FORMULATION}

\subsection{The System}

The system under consideration is a full-size passenger hybrid electric vehicle with a parallel drivetrain as illustrated in Figure 1. The vehicle is modeled using a standard quasistatic backwards approach as described by [1]. The vehicle velocity, acceleration, and gear number are input signals obtained from driving cycle data, while a supervisory control input $u(t)$ determines the torque split factor between the engine and the electric motor at every time step. The model has a single dynamic state $x(t)$ which is the state-ofcharge of the battery. The output of the model is the fuel

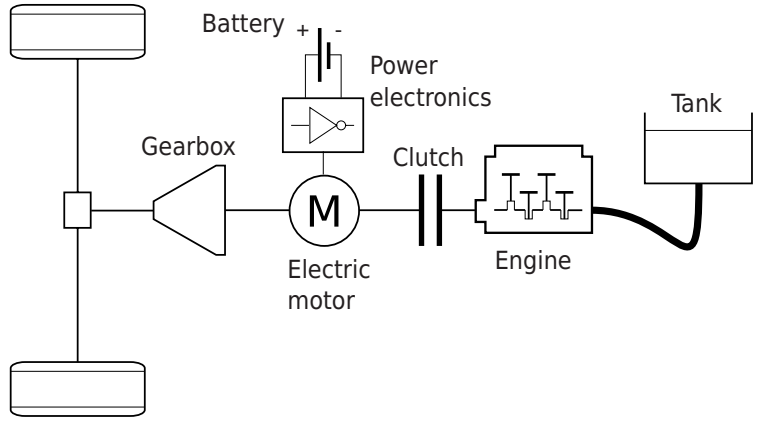

Figure 1

The parallel hybrid electric vehicle drivetrain.

consumption of the combustion engine. The vehicle model is described in detail in Appendix A.

The optimal control input is the energy management strategy that globally minimizes the total amount of fuel consumed by the engine over the entire driving cycle. This strategy is found by solving an optimal control problem by means of deterministic dynamic programming, see [2]. The optimal control problem is described in detail in Appendix B.

\subsubsection{Model Scaling}

The mathematical models of the three drivetrain components subject to optimization must be scalable. The scaling methodology of each component is described below.

The engine model is based on a Willans approximation and assumes a constant bore-to-stroke ratio. In this way, fuel consumption, maximum engine torque and speed scale with engine displacement volume $V_{d}$ (liter) according to the equations given in Appendix A.

The model of the electric motor assumes that the electric power map, torque constraints, motor mass and inertia scale linearly with the maximum motor power $P_{m}(\mathrm{~kW})$.

The battery model is based on data from the ADVISOR library [3]. It assumes constant open-circuit voltage $V_{\text {oc }}=240 \mathrm{~V}$ and constant maximum current-to-capacity ratio. Thus, battery current constraints and maximum power both scale linearly with battery capacity $Q_{0}(\mathrm{Ah})$. The mass of the battery is also scaled linearly with capacity and therefore the specific energy of the reference battery of about $50 \mathrm{Wh} . \mathrm{kg}^{-1}$ remains constant for all battery sizes.

\subsubsection{Performance and Drivability}

Certain performance and drivability metrics remain important to consumer acceptance. The most notable quantifier is acceleration performance, i.e., the time needed for the vehicle to accelerate for 0 to $100 \mathrm{~km} / \mathrm{h}$. Simple algebraic approximations of acceleration performance exist [1]. However, in this study, we estimated the acceleration performance 
by means of quasi-static simulation. This is necessary in order to track the state-of-charge of the battery during the acceleration. In turn, the particular combination of engine, motor and battery size is discarded if the battery is depleted below its lower bound during the acceleration starting from the initial state-of-charge $x_{0}$, (cf. Appendix B).

Two additional quantifiers of performance was considered, namely vehicle top speed $v_{\max }$ and grade-ability $v_{\min }(\alpha)$ which is the minimum vehicle speed at grade angle $\alpha$ with $300 \mathrm{~kg}$ payload. Both quantifiers are also estimated using quasi-static simulation. Note that in order to sustain $v_{\max }$ and $v_{\min }$ over longer periods they both depend exclusively on the maximum engine power rather than on the combined power of the engine and the electric path.

\subsubsection{Total Cost of Hybridization}

We assumed the total monetary cost of hybridization (unit: $€$ ) is the sum of three contributions: the cost of the engine:

$$
c_{\mathrm{e}}=15 \cdot P_{e}(\mathrm{~kW})
$$

the cost of the electric motor including power electronics:

$$
c_{\mathrm{m}}=30 \cdot P_{m}(\mathrm{~kW})
$$

and finally, the cost of the battery including packaging:

$$
c_{\mathrm{b}}=600 \cdot Q_{0}(\mathrm{kWh})
$$

All linear approximations above are assumed.

\subsection{Optimization Problem}

The optimal sizing problem considered in this paper is to find the triple of parameters $p=\left\{V_{d}, P_{m}, Q_{0}\right\}$ that minimize the objective function $f(p)$ subject to a number of inequality constraints $g(p) \leq 0$. Both the objective and the constraints are non-convex functions with respect to $p$.

We defined the objective function $f(p)$ as a weighted sum of fuel consumption, cost of hybridization and the acceleration performance of the vehicle, that is:

$$
f(p)=\sum_{i=1}^{3} w_{i} \cdot f_{i}(p), \quad w_{i} \wedge f_{i} \in[0,1]
$$

where:

$$
1=w_{1}+w_{2}+w_{3}
$$

The term $f_{1}(p)$ is the lowest possible fuel consumption given the parameters $p$ and the optimal energy management strategy. This term is computed by means of dynamic programming. The driving cycle used was the New European Driving Cycle (NEDC). The second term $f_{2}(p)$ is the total cost of hybridization. The third term $f_{3}(p)$ is the acceleration performance of the vehicle. All terms $f_{i}(p)$ for $i=\{1,2,3\}$ are normalized such that $f_{i}(p)$ attain values between zero and one. Note that the objective function can easily be extended to include other quantifiers such as emission levels.

With the weights $w_{i}$, the vehicle can be tailored to different market segments. For example, a certain segment may prioritize fuel economy at a reasonable cost with no particular preference towards acceleration performance. In this case, $w_{1}=0.7, w_{2}=0.3$, and $w_{3}=1-w_{1}-w_{2}=0$ may represent a reasonable choice of weights. Obviously, the weights may be adjusted to match any other market segment of interest.

The inequality constraints $g(p) \leq 0$ are set to guarantee a certain level of performance and drivability. In this study, we considered:

$$
v_{\max } \geq 130 \mathrm{~km} \cdot \mathrm{h}^{-1}, \quad v_{\min }\left(\alpha=6.4^{\circ}\right) \geq 90 \mathrm{~km} \cdot \mathrm{h}^{-1} .
$$

Moreover, we bounded the search space using simple lower and upper constraints to ensure a well-posed problem, that is:

$$
\begin{aligned}
0.6 \mathrm{~L} & \leq V_{d} \leq 1.6 \mathrm{~L} \\
1 \mathrm{~kW} & \leq P_{m} \leq 50 \mathrm{~kW} \\
1 \mathrm{Ah} & \leq Q_{0} \leq 20 \mathrm{Ah}
\end{aligned}
$$

Note that we have not imposed an upper bound on the acceleration performance. However, this quantifier can be directly influenced by adjusting the weight $w_{3}$ accordingly. Furthermore, as it turns out, the constraints on $v_{\max }$ and $v_{\min }$ do not restrict the search space because they can be fulfilled even with a 0.6 liter engine.

\section{METHODOLOGY}

We solved the optimal sizing problem using an exhaustive search methodology. An exhaustive search means that the three-dimensional search space defined by Equations (7-9) is first gridded by discretization. Then, fuel consumption, acceleration performance and cost of hybridization is computed on every node in the entire grid. The results $f_{i}(p) \forall p$ are stored in three-dimensional look-up tables. Subsequently, the objective function $f(p)$ can be minimized for any arbitrary set of weights $w_{i}$ in fractions of a second. The accuracy of this method depends on the integrity of the grid. In the current study, we discretized the search space by twenty-four equally spaced nodes in each of the three directions, i.e., $24^{3}=13824$ nodes in total.

Particle swarm optimization [4], generic algorithms [5], and deterministic search methods, such as Nelder-Mead simplex algorithm (fminsearch) [6], was suggested as efficient search methods to solve the optimal sizing problem [7-10]. However, here, pre-computing $f_{i}(p) \forall p$ is more efficient because once $f_{i}(p)$ are obtained, the sizing problem can be solved repeatedly with minimal computational effort for any combination of weights. This is particularly 


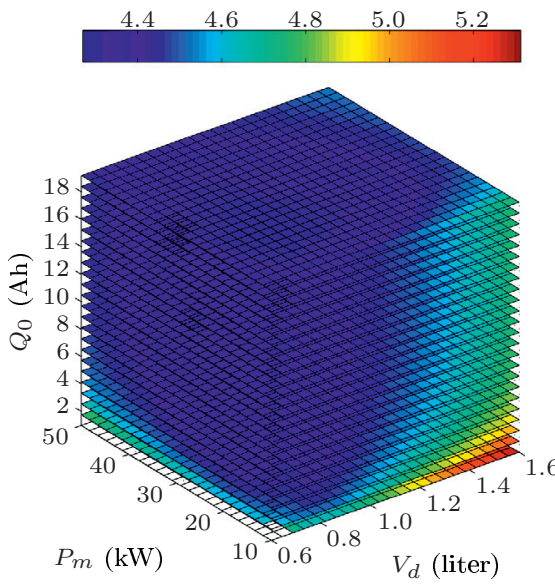

a)

Figure 2

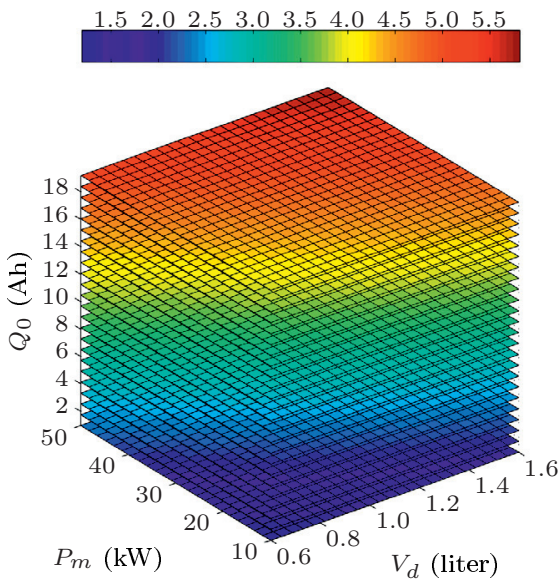

b)

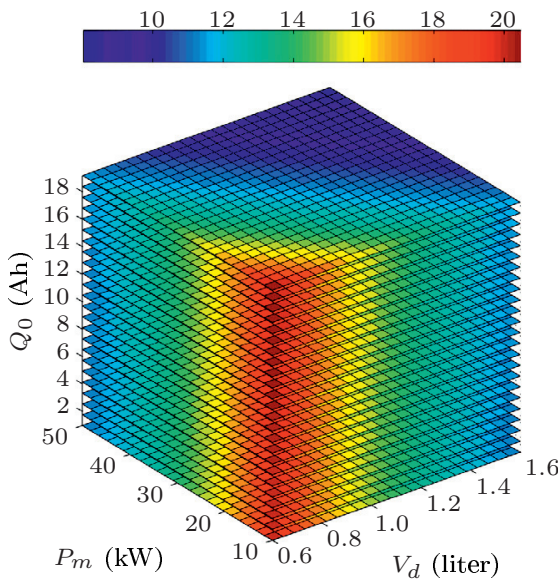

c)

a) Fuel economy $(1 / 100 \mathrm{~km}), \mathrm{b})$ cost of hybridization $\left(\times 10^{3} €\right)$, and c) acceleration performance (s).

important when performing, e.g., a Pareto analysis where the solutions to a large number of different sets of weights are sought.

In fact, we did perform a Pareto analysis in order to study the influence of the weights $w_{i} \in[0,1]$ on the optimal sizing and thus on $f_{i}(p)$. Each of the three weights were discretized by sixty-one linearly spaced nodes, i.e., $61^{3}=226981 \mathrm{com}-$ binations in total. However, only the combinations complying with the condition of Equation (5) were considered.

In addition, a simple sensitivity analysis was performed to investigate the relative influence of changes in the three parameters $p=\left\{V_{d}, P_{m}, Q_{0}\right\}$ on the optimal solution in terms of $f_{i}(p)$. Each of the three parameters $p_{j}, j=\{1,2,3\}$ was perturbed with $10 \%$ of its optimal value and the variation in the objective function terms $f_{i}, i=\{1,2,3\}$ observed. The sensitivity of $f_{i}$ with respect to the perturbation in parameter $p_{j}$ was calculated using the following definition:

$$
S_{i j}=\frac{\partial f_{i}}{\partial p_{j}} \cdot \frac{p_{j}}{f_{i}}
$$

where the term $p_{j} / f_{i}$ normalizes the partial derivatives. The values of $S_{i j}$ indicate the percentage change in $f_{i}$ if parameter $p_{j}$ is perturbed by one percent.

\section{RESULTS}

As explained above, the three terms $f_{i}(p)$ were precomputed for all nodes in the discretized search space and stored in three-dimensional look-up tables. Figure 2 shows the resulting look-up table for each term. Note that the minima of $f_{i}(p)$ reside in very different locations of the search space. This observation validates the necessity to trade-off the three terms. The complexity of the sizing problem is further emphasized by the non-linearities visible in the fuel consumption table.

Figure 2 also indicates the approximate range of values to be expected of each term. As seen, fuel consumption ranges from about 4.5 to $5.3 \mathrm{~L} / 100 \mathrm{~km}$; cost of hybridization from 1400 to $5700 €$; and finally, acceleration performance from about 8 to $21 \mathrm{~s}$. Consequently, while fuel consumption may be reduced somewhat $(-15 \%)$ with respect to the least fuel efficient parameterization, the potential of reducing cost $(-75 \%)$ and acceleration time $(-62 \%)$, by proper choice of engine, electric motor, and battery, is significantly larger

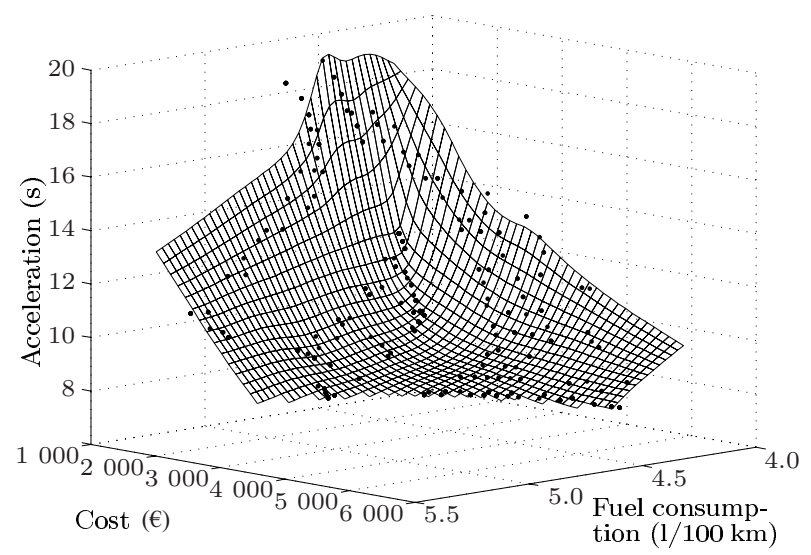

Figure 3

Pareto frontier indicating the optimal trade-off between fuel economy, cost, and acceleration performance. 
TABLE 1

Numerical values of selected weights

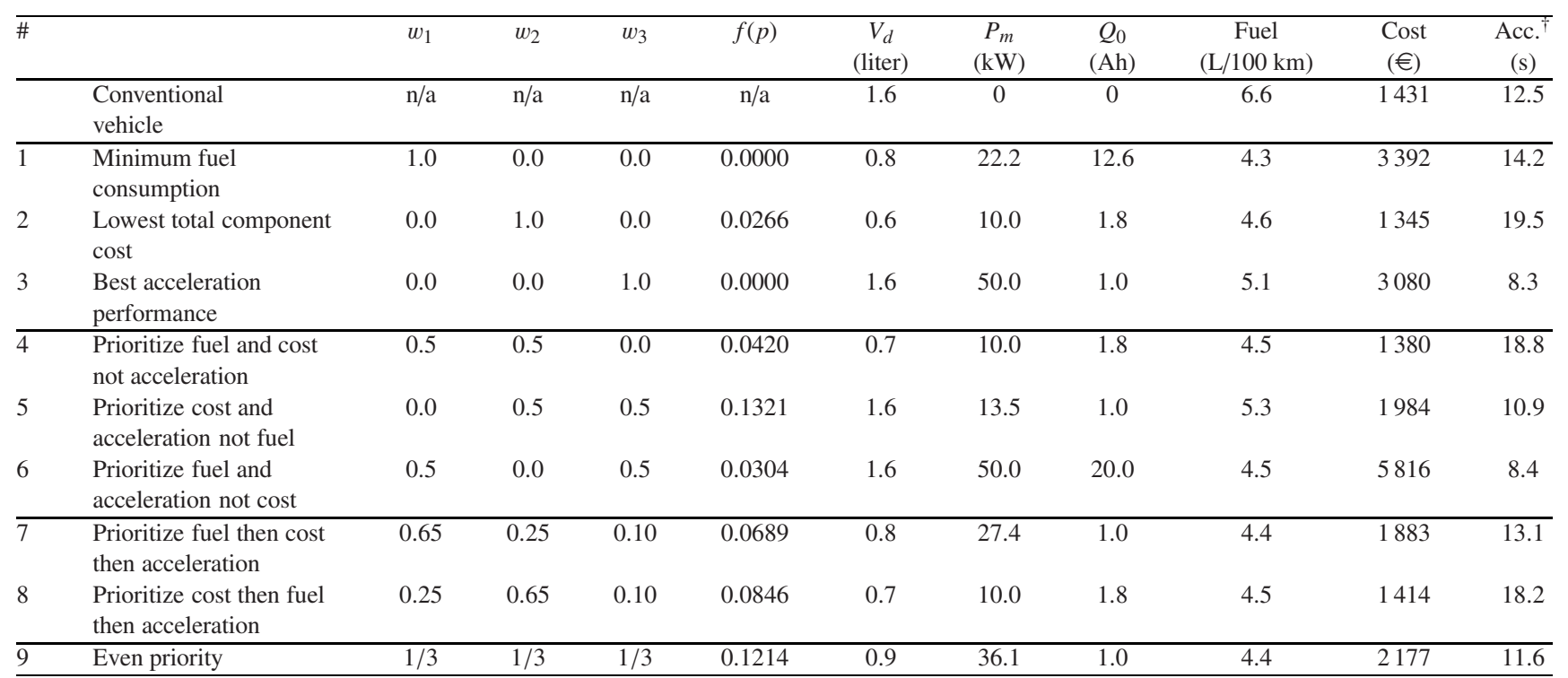

$\dagger$ Acceleration from 0 to $100 \mathrm{~km} / \mathrm{h}$.

\subsection{Pareto Analysis}

Figure 3 shows the results of the Pareto analysis. Each dot in the figure represents the optimal solution to the sizing problem given a unique set of weights $\left\{w_{1}, w_{2}, w_{3} \mid w_{1}+w_{2}+w_{3}=1\right\}$. The fitted surface represents the Pareto frontier depicting the optimal trade-off between fuel-consumption, cost and acceleration performance. Note that it is sub-optimal to be above the surface, i.e., there exists a different $p$ that enhances at least one of the three terms $f_{i}(p)$ without degrading the others. Moreover, it is "super-optimal" (impossible) to be below the surface, i.e., there exists no $p$ that realize those specific values of $f_{i}(p)$ simultaneously.

Table 1 shows the numerical details of the optimal solution for nine distinct sets of weights, including the properties of a conventional vehicle with a 1.6 liter engine. The first three solutions (\#1, \#2, and \#3) prioritize a single term in the objective function only. Consequently, they establish the best possible fuel economy, lowest cost and best acceleration performance, respectively and thus they serve as a reference for the remaining six solutions with two or three non-zero priorities. A number of observations are, among others, worth noting, namely:

- the cheapest vehicle (\#2) is also the slowest accelerating vehicle;

- the most expensive vehicle (\#6) is practically on par with the fuel economy of the most fuel efficient vehicle (\#1) and the acceleration performance of the fastest accelerating vehicle (\#3). Yet, the cost is almost twice as high as either one of these;

- the battery should only be larger than its minimum size, i.e., the size necessary to complete the acceleration from

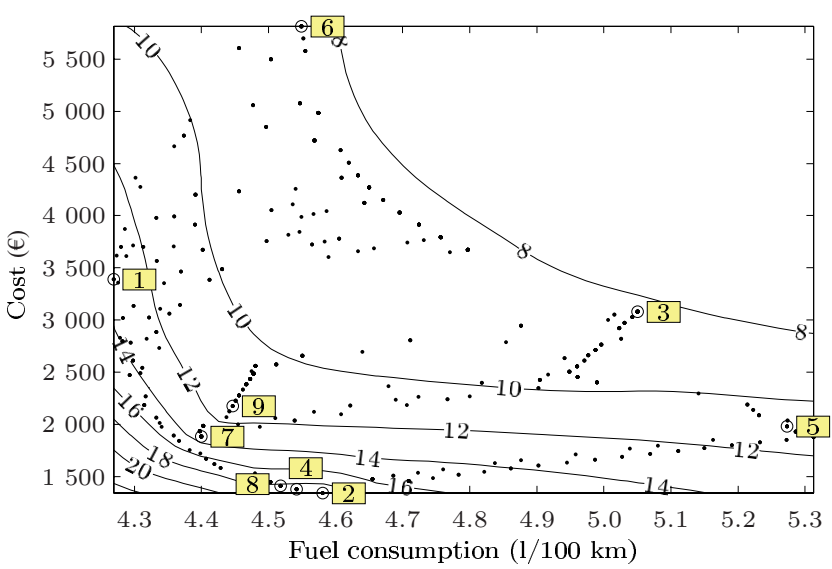

Figure 4

Location of selected nine solutions on the Pareto frontier. The contour lines reflect iso-acceleration performance (s).

0 to $100 \mathrm{~km} / \mathrm{h}$ without depleting, if fuel economy is prioritized with no consideration on cost;

- prioritizing only cost and acceleration performance yields the least fuel efficient vehicle (\#5);

- a gradual priority (\#7) and even priority (\#9) seem to yield good compromises between fuel economy, cost and acceleration performance.

Figure 4 indicates the location of the nine solutions on the Pareto frontier. The figure suggests that reasonable compromises between the three terms $f_{i}(p)$, such as \#7 and \#9, reside in the lower left corner of the graph at the foot of the steep inclination (degradation) in acceleration performance. 


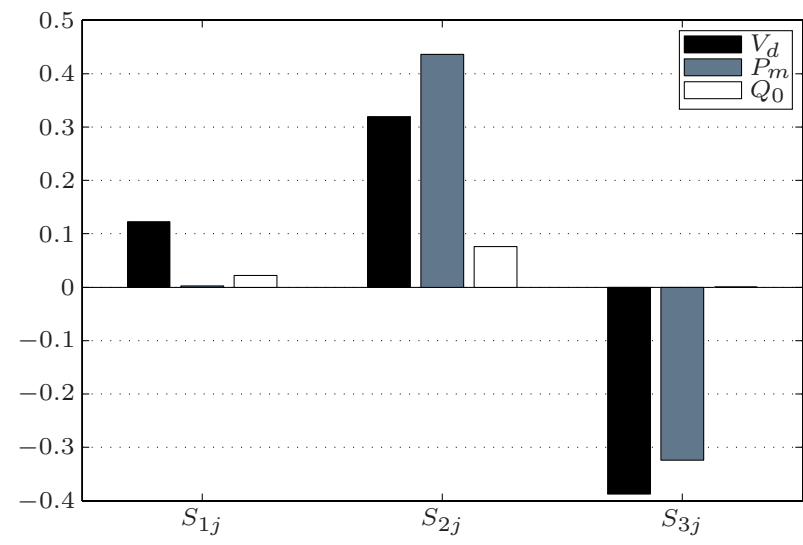

Figure 5

Sensitivity analysis: the relative influence of changes in $p$ on the optimal solution of \#7.

A lot of additional information can be inferred from Figure 4. For example, moving along a curve of constant acceleration performance, say $10 \mathrm{~s}$, it can be seen that a relatively low increase in cost harvest the largest part of the total fuel saving potential - or, stated the other way around, starting from the most fuel efficient parameterization and considering constant acceleration performance, the total cost may be reduced significantly with only a small penalty on fuel economy.

\subsection{Sensitivity}

The sensitivity analysis is demonstrated for the optimal solution \#7 as an example. Yet, this analysis can be repeated for any other solution of interest. Figure 5 shows the normalized sensitivities $S_{i j}$. As seen, increasing the engine size by $1 \%$ yields approximately $0.12 \%$ higher fuel consumption and $0.32 \%$ higher cost. In contrast, acceleration performance is improved by about $0.38 \%$. Increasing the size of the electric motor by $1 \%$, has no notable influence on fuel economy but has a strong positive influence on acceleration performance. However, the cost incurred by increasing its size renders a larger motor unattractive.

Finally, increasing the size of the battery has the smallest influence on the total cost. This results may seem counterintuitive since Li-ion batteries are commonly recognized as being expensive compared to other components. However, in case \#7, the battery is relatively small, so the cost incurred by increasing its size $1 \%$ accounts only for small fraction of the total cost. A larger battery causes a marginal increase in fuel consumption, due to the additional weight, and has no notable effect on acceleration performance. Consequently, there are no benefits of increasing the size of the battery further.

\section{CONCLUSION}

The need for a systematic approach to engine downsizing and electric hybridization under consideration of drivability and cost led us to develop the unified framework for optimal sizing presented in this paper.

The results showed that, by formalizing the sizing problem in an optimization theoretical setting, intelligent nontrivial solutions can be obtained with little effort. These solutions did not only meet basic expectations such as low fuel consumption, but did so at lowest possible cost and best possible acceleration performance.

The framework is flexible and can be extended to include other measures of performance such as emission levels. In addition, the objective function, composed of weighted and normalized terms, allowed us to steer the solution towards specific market segments using intuitive tuning methods. A linear scaling method is not mandatory.

Future works include extensions to the objective function and further analysis of the properties of the Pareto frontier and the sensitivity analysis.

\section{ACKNOWLEDGEMENTS}

This research project is supported by Daimler AG.

\section{APPENDIX}

\section{A VEHICLE MODEL}

The rotational speed $\omega_{\mathrm{w}}$, rotational acceleration $\dot{\omega}_{\mathrm{w}}$ and torque $T_{\mathrm{w}}$ at the wheels are derived from vehicle velocity $v$, acceleration $a$ and slope angle $\alpha$ dictated by the driving cycle:

$$
\begin{aligned}
& \omega_{\mathrm{w}}=v / r_{\mathrm{w}}, \quad \dot{\omega}_{\mathrm{w}}=a / r_{\mathrm{w}} \\
& T_{\mathrm{w}}=\left(F_{i}+F_{a}+F_{r}+F_{g}\right) \cdot r_{\mathrm{w}}
\end{aligned}
$$

where $r_{\mathrm{W}}$ is the radius of the wheels. The signals $v, a, \alpha$ are discretised with a sampling period of $1 \mathrm{~s}$. The inertial forces, aerodynamic drag, rolling friction, and gravitational forces are is given by:

$$
\begin{aligned}
F_{i} & =\left(m_{\mathrm{veh}}+m_{\mathrm{rot}}\right) \cdot a \\
F_{a} & =1 / 2 \cdot \rho_{\mathrm{air}} \cdot A_{f} \cdot c_{d} \cdot v^{2} \\
F_{r} & =\left(c_{\mathrm{r} 0}+c_{\mathrm{r} 1} \cdot v^{c_{\mathrm{r} 2}}\right) \cdot m_{\mathrm{veh}} \cdot g \cdot \cos (\alpha) \\
F_{g} & =m_{\mathrm{veh}} \cdot g \cdot \sin (\alpha)
\end{aligned}
$$

respectively, where $m_{\text {rot }}$ is the equivalent mass of the moment of inertia of the rotating components in the drivetrain. The total vehicle mass is $m_{\mathrm{veh}}=m_{0}+m_{e}+m_{m}+m_{b}$ where $m_{0}$ is the constant nominal vehicle mass, engine mass $m_{e}$, motor mass $m_{m}$, and battery mass $m_{b}$. Table 2 summarizes the numerical values of all constant parameters needed to parametrize Equation (A.1) through (A.6). 
TABLE 2

Vehicle parameters

\begin{tabular}{lll}
\hline Parameter & Description & Value \\
\hline$r_{\mathrm{w}}$ & Wheel radius & $0.31 \mathrm{~m}$ \\
$m_{0}$ & Nominal vehicle mass & $1500 \mathrm{~kg}$ \\
$A_{f}$ & Effective frontal area & $2.54 \mathrm{~m}^{2}$ \\
$c_{d}$ & Aero. drag coefficient & 0.315 \\
$c_{\mathrm{r} 0}, c_{\mathrm{r} 1}, c_{\mathrm{r} 2}$ & Rolling friction & $0.09,3.8 \cdot 10^{-5}, 1.4$ \\
\hline
\end{tabular}

\section{Gearbox}

The gearbox is modeled using a constant efficiency $\eta_{\mathrm{gb}}=0.95$ and six gears with the gear ratios $\gamma_{i}$ for $i=\{1, \ldots, 6\}$. The conversion between input and output torque and speed of the gearbox is:

$$
\begin{aligned}
& \omega_{\mathrm{gb}}=\gamma_{i} \cdot \omega_{\mathrm{w}}, \quad \dot{\omega}_{\mathrm{gb}}=\gamma_{i} \cdot \dot{\omega}_{\mathrm{w}} \\
& T_{\mathrm{gb}}=\left\{\begin{array}{l}
\frac{T_{\mathrm{w}}}{\gamma_{i} \cdot \eta_{\mathrm{gb}}} \text { for } T_{\mathrm{w}} \geq 0 \\
\frac{T_{\mathrm{w}} \cdot \eta_{\mathrm{gb}}}{\gamma_{i}} \text { for } T_{\mathrm{w}}<0
\end{array}\right.
\end{aligned}
$$

\section{Internal Combustion Engine}

The internal combustion engine is modeled using a Willans approximation as explained in [11], where the mean effective cylinder pressure is approximated by an affine function of mean effective fuel pressure $p_{\mathrm{mf}}$, that is:

$$
p_{\mathrm{me}} \approx e\left(\omega_{e}\right) \cdot p_{\mathrm{mf}}-p_{\mathrm{me} 0}\left(\omega_{e}\right)
$$

where $e\left(\omega_{e}\right)$ is the indicated efficiency and $p_{\mathrm{me} 0}\left(\omega_{e}\right)$ is the mean effective pressure loss due to friction, gas exchange, and auxiliary devices. The total torque loss including inertial torque of the engine is then given by:

$$
T_{\mathrm{e} 0}=\Theta_{e} \cdot \dot{\omega}_{e}+\frac{V_{d} \cdot p_{\mathrm{me} 0}\left(\omega_{e}\right)}{4 \pi}
$$

where $\Theta_{e}$ is the inertia of the engine, $V_{d}$ is the displacement volume, and $\omega_{e}=\omega_{\mathrm{gb}}$ if the clutch connecting the engine to the crankshaft is locked. The fuel power consumption $P_{f}(\mathrm{~W})$ is calculated using:

$$
P_{f}=\frac{p_{\mathrm{mf}} \cdot \omega_{e} \cdot V_{d}}{4 \pi}
$$

The mass of the engine is assumed to be given by the following relation [12]

$$
m_{e}=67.6 \times 10^{3} \mathrm{~kg} \cdot \mathrm{m}^{-3} \cdot V_{d}
$$

This approximation is assumed to hold for $V_{d} \geq 0.6$ liter. Figure 6 shows the fuel consumption, torque and speed limitations of the $1.6 \mathrm{~L}$ reference engine.

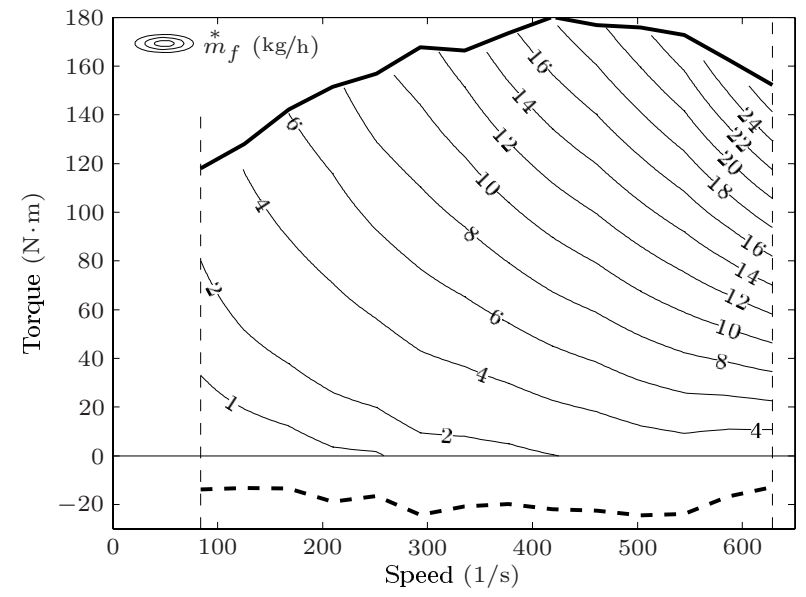

Figure 6

Fuel consumption map of the reference engine including maximum engine torque (bold) and the torque loss (bold dashed).

\section{Electric Motor}

The model of the electric motor is based on a $25 \mathrm{~kW}$ permanent magnet synchronous machine. The inertial torque of the motor is:

$$
T_{\mathrm{m} 0}=\Theta_{m} \cdot \dot{\omega}_{m}
$$

where $\Theta_{m}$ is the inertia of the motor. An electric power map is used to obtain the electric power either drawn from or supplied to the battery from the motor, i.e., $P_{m}=\Gamma\left(\omega_{m}, T_{m}\right)$. The motor torque is limited by a set of speed dependent nominal torque inequality constraints $T_{m, \min }\left(\omega_{m}\right) \leq T_{m} \leq$ $T_{m, \max }\left(\omega_{m}\right)$. The mass of the electric machine is assumed to be:

$$
m_{m}=2.2(\mathrm{~kg} / \mathrm{kW}) \cdot P_{m}
$$

for $P_{m} \geq 1 \mathrm{~kW}$. Figure 7 shows the efficiencies, torque and speed limitations of the $25 \mathrm{~kW}$ reference motor.

\section{Torque Split}

The input control signal $u(t)$ defines how the total torque demand $T_{\mathrm{dem}}(t)$ at the gearbox input is split between the engine and electric motor, i.e.,

$$
\begin{aligned}
T_{m} & =u \cdot T_{\mathrm{dem}} \\
T_{e} & =(1-u) \cdot T_{\mathrm{dem}}
\end{aligned}
$$

Note that during recuperation and pure electric driving the clutch between the engine and the crankshaft is open, thus:

$$
T_{\mathrm{dem}}= \begin{cases}T_{\mathrm{gb}}+T_{\mathrm{m} 0} & \text { if } u=1 \\ T_{\mathrm{gb}}+T_{\mathrm{m} 0}+T_{\mathrm{e} 0} & \text { otherwise }\end{cases}
$$




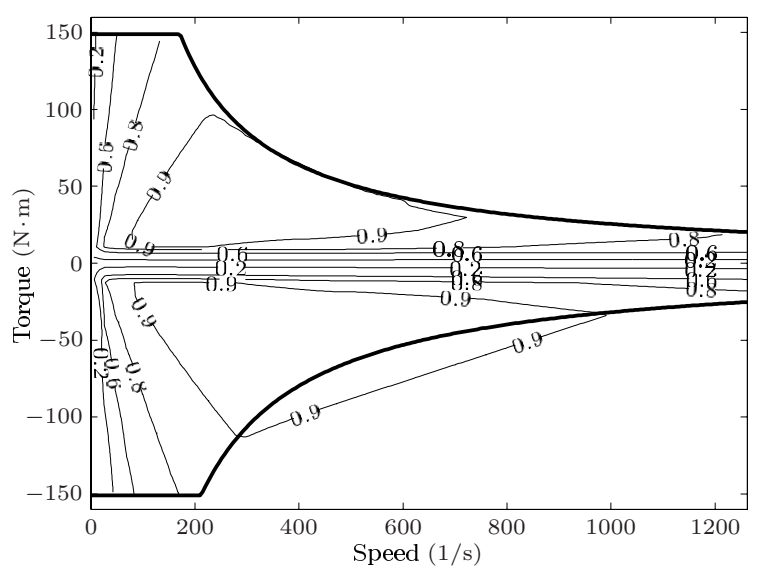

Figure 7

Efficiency map of the reference motor inducing maximum and minimum torque limitations.

\section{B OPTIMAL CONTROL PROBLEM}

The optimal control problem consists of finding the optimal control strategy $u^{o}(t) \forall t \in[0, T]$ that, subject to a number of constraints, minimizes the total amount of fuel consumed over a given driving cycle. This optimization problem takes the following mathematical form:

$$
\min _{u}: \quad \int_{0}^{T} \stackrel{*}{m}_{f}(u(t), t) d t
$$

subject to:

$$
\begin{aligned}
\dot{x}(t) & =-\eta_{b} \cdot I_{b} / Q_{0} \\
x(0) & =x_{0} \\
x(T) & \geq x_{0} \\
x(t) & \in\left[x_{\min }, x_{\max }\right] \\
u(t) & \in[-\infty, 1]
\end{aligned}
$$

where $x(t)$ is the state-of-charge of the battery with the initial state $x_{0}=0.6$. Furthermore, $x(t)$ is bounded by $x_{\min }=0.3$ and $x_{\max }=0.9$ for improved battery life.

This optimal control problem is solved numerically using deterministic dynamic programming. In order to reduce run-time and numerical errors, we used the computationally efficient generic dynamic programming MATLAB function of [13]. An optimal solution $u^{o}(t)$ and the corresponding fuel consumption was obtained in about one minute on average.

\section{REFERENCES}

1 Guzzella L., Sciarretta A. (2007) Vehicle Propulsion Systems: Introduction to Modeling and Optimization, 2nd ed., Springer.

2 Bertsekas D.P. (2005) Dynamic Programming and Optimal Control, Vol. 1, 3rd ed., Athena Scientific.

3 Wipke K.B., Cuddy M.R., Burch S.D. (1999) Advisor 2.1: a user-friendly advanced powertrain simulation using a combined backward/forward approach, IEEE Trans. Vehic. Technol. 48, 6, 1751-1761.

4 Kennedy J., Eberhart R. (1995) Particle swarm optimization, in Neural Networks, 1995. Proceedings, IEEE International Conference on, Vol. 4, 21 Nov-1 Dec., pp. 1942-1948.

5 Goldberg D.E. (1989) Genetic Algorithms in Search, Optimization and Machine Learning, 1st ed., Addison-Wesley Professional.

6 Nelder J.A., Mead R. (1965) A simplex-method for function minimization, Comput. J. 7, 4, 308-313.

7 Wenzhong Gao, Mi C. (2007) Hybrid vehicle design using global optimisation algorithms, Int. J. Electric Hybrid Vehicles 1, 57-70.

8 Hegazy O., Van Mierlo J. (2010) Particle swarm optimization for optimal powertrain component sizing and design of fuel cell hybrid electric vehicle, in Optimization of Electrical and Electronic Equipment (OPTIM), 2010 12th International Conference on, 20-22 May, pp. 601-609.

9 Wu J., Zhang C., Cui N. (2008) PSO algorithm-based parameter optimization for HEV powertrain and its control strategy, Int. J. Automotive Technol. 9, 1, 53-59.

10 Xiaolan $\mathrm{Wu}$, Binggang Cao, Jianping Wen, Zhanbin Wang (2008) Application of particle swarm optimization for component sizes in parallel hybrid electric vehicles, in Evolutionary Computation (CEC 2008), IEEE Congress on, Hong Kong, 1-6 June, pp. 2874-2878.

11 Guzzella L., Onder C.H. (2004) Introduction to Modeling and Control of Internal Combustion Engine Systems, 1st ed., Springer.

12 Sundstrom O., Guzzella L., Soltic P. (2008) Optimal hybridization in two parallel hybrid electric vehicles using dynamic programming, in Proceedings of the 17th IFAC World Congress, Seoul, Korea, Vol. 17, Part 1, pp. 4642-4647.

13 Sundstrom O., Guzzella L. (2009) A generic dynamic programming matlab function, in Control Applications, $(C C A) \mathcal{F}$ Intelligent Control, (ISIC), 2009 IEEE, 8-10 July, pp. 16251630. 